\title{
Dadru (Skin Disease): A Case Report
}

\author{
Chambyal $\mathrm{K}^{1 *}$ and Yadav $\mathrm{CR}^{2}$ \\ ${ }^{1}$ PG Scholar, Department of śarīra kriyā, NIA, India \\ ${ }^{2}$ Associate Professor, P.G Department of śarīra kriyā, NIA, India
}

*Corresponding author: Kavita Chambyal, National Institute of Ayurveda, Jaipur, Rajasthan, India, Tel: 9459803463; Email: kabu.thakur988@gmail.com

\section{Case Report \\ Volume 4 Issue 3}

Received Date: September 06, 2019

Published Date: September 23, 2019

DOI: $10.23880 /$ cdoaj-16000189

\section{Abstract}

Skin is the outermost layer of body which protects body from direct contact of surrounding environment. The skin also secretes some secretions which are protective in nature by their killing or inhibiting action on some microorganisms. Dadru is pitta kapha vyādhi which simulates clinically with Tinea corporis. The symptoms are Itching, redness with elevated pidikā, scaly lesions. In this study, a female patient with average built 42 years came with complaints of itching, rashes, scaly lesions and was diagnosed to suffer from dadru. A composite of āyurveda treatment- malla sindūra -125mg B.D, śuddh gandhakaa cūrṇa-1g B.D, rasamāṇikya -125mg B.D, nimbādi cūrṇa -1g B.D (anti-helminthic), manjișthā cūrṇa$1 \mathrm{~g}$ B.D, haridrākhanḍa-1tsp B.D, kaiśora guggulu-2 tab(250mg) B.D., dadruharalepa for local application B.D, taruṇikusumākara cūrṇa with lukewarm water only during sleeping time, these medicines were given to patient. Some dietary and life style changes were also advised to her. After follow up of seven days, significant results were seen in kạ̣du, redness and scaly lesions.

Keywords: Dadru; Tvaka; Cikitsa

\section{Introduction}

Skin is the protective layer of whole body and also called "tvaka". According to āyurveda, it is upadhātu of mānsadhātu [1-3]. Dadru occurs on cells in the outer layer of skin. Itching, redness with elevated pidikā, alasi flower \& copper like colour [4] are symptoms of this disease according to āyurveda. ācārya caraka kept dadru under the concept of kśudra kuștha which is pitta kapha vyādhi [5]. According to suśruta, this vyadhi comes under mahākuștha \& is kapha pradhāna vyadhi [6]. In āyurveda, tvacāgatakuștha like dadru, the treatment given is shodhana lepana [7]. So mild purgative, tarunīkusumākara cūrṇa is also used for this purpose. Ācārya vāgbhațta said, kuștha which is present in tvaka, the symptoms are toda, vaivarṇya \& rūkșatā [8]. Rasa \& rakta dhātu dușți also occur in the pathogenesis of dadru \& it is spreading like dūrvāvāta (dīrghapratānā) [9] in whole body.

\section{Case Report}

A female patient with average built 42 years was treated in OPD, Department of śarīra kriyā, National Institute of ayurveda, Jaipur with chief complaints of itching and rashes in bilateral inguinal region, under breast area, on left thigh, left forearm and lower abdomen (belt area). Patient had given the history of constipation, pain in epigastric region \& white discharge per vagina sometimes. She has also giving the history of hypothyroidism and taking medication since six years. 


\section{Clinical Dermatology Open Access Journal}

TSH level is $5.29 \mathrm{uI} / \mathrm{mL}$, B.P- $126 / 88$, P.R- $80 / \mathrm{min}$., weight- $70 \mathrm{~kg}$, height- 5.7 .

After the examination, this patient was diagnosed to suffering from dadru (Tinea corporis infection) \& a composite āyurveda treatment was given. Malla sindūra $125 \mathrm{mg}$ B.D, shuddha gandhaka cūrṇa-1g B.D, rasamāṇikya-125mg B.D, nimbādi cūrṇa-1g B.D ( antihelminthic), manjișthā cūrṇa-1g B.D, haridrākhanḍa-1tsp B.D, kaiśora guggulu-2 tab B.D (250mg), dadruharalepa two times for local application, tarunīkusumākara cūrṇa$5 \mathrm{~g}$ with lukewarm water only during sleeping time, these medicines were given to the patient. Satisfactory results were found after 7 days of treatment.

\section{Dietary and Life Style Modifications}

Patient is advised to avoid sour, salted food, incompatible food, oily, spicy, junk/fast food, cold water, non- vegetarian food, avoid tight fitted clothes, avoid daytime sleep and also suggested to maintain personal hygiene.

\begin{tabular}{|c|c|c|c|c|c|c|c|c|c|}
\hline $\begin{array}{l}\text { S. } \\
\text { No. }\end{array}$ & Drug Name & $\begin{array}{c}\text { Botanical } \\
\text { Name }\end{array}$ & Family & Rasa & Guṇa & Virrya & Vipāka & Prabhāva & Doșa Karma \\
\hline 1. & Manjișthā [10] & $\begin{array}{c}\text { Rubia } \\
\text { cordifolia } \\
\end{array}$ & Rubiaceae & $\begin{array}{c}\text { Tikta, kașāya, } \\
\text { madhura }\end{array}$ & gurū, rūkșa & Ūṣna & Katu & $\begin{array}{c}\text { Varnya, } \\
\text { kușthaghna }\end{array}$ & $\begin{array}{l}\text { Kapha pitta } \\
\text { śāmaka }\end{array}$ \\
\hline 2. & Nimba [11] & $\begin{array}{c}\text { Azadirachta } \\
\text { indica }\end{array}$ & Meliaceae & Tikta, kașāya & Laghu & Śita & Katu & $\begin{array}{l}\text { kușthaghna, } \\
\text { krumihara, } \\
\text { kaṇdughana }\end{array}$ & $\begin{array}{l}\text { Kapha pitta } \\
\text { śāmaka }\end{array}$ \\
\hline 3. & Haridrā [12] & $\begin{array}{l}\text { Curcuma } \\
\text { longa }\end{array}$ & Zingiberacae & Tikta, katu & Rūkșa, laghu & U̦șṇa & Katu & $\begin{array}{c}\text { Varnya, } \\
\text { krumihara, } \\
\text { kaṇdughana }\end{array}$ & $\begin{array}{l}\text { Tridoșa } \\
\text { śāmaka }\end{array}$ \\
\hline 4. & Taruṇī [13] & $\begin{array}{c}\text { Rosa } \\
\text { centifolia }\end{array}$ & Rosaceae & $\begin{array}{l}\text { Tikta, kașāya, } \\
\text { madhura }\end{array}$ & Laghu, snigdha & Síta & Madhura & Hrudya, varnya & $\begin{array}{l}\text { Kapha pitta } \\
\text { śāmaka }\end{array}$ \\
\hline 5. & \begin{tabular}{|} 
Sarala niryasa \\
{$[14]$}
\end{tabular} & $\begin{array}{c}\text { Pinus } \\
\text { roxurghii }\end{array}$ & Pinaceae & $\begin{array}{l}\text { Katu, tikta, } \\
\text { madhura }\end{array}$ & $\begin{array}{l}\text { Laghu, tikshna, } \\
\text { snigdha }\end{array}$ & Ūṣna & Katu & kușthaghna & $\begin{array}{l}\text { Kaphavāta } \\
\text { śāmaka }\end{array}$ \\
\hline 6. & Gandhaka [15] & & & Katu, tikta, & $\begin{array}{c}\text { Sara, Balya, vrșya } \\
\text { brnhana }\end{array}$ & U̦șna & Madhura & $\begin{array}{c}\text { Kandudu, kușțha, } \\
\text { dadru nāśaka }\end{array}$ & $\begin{array}{c}\text { Pittavardhaka, } \\
\text { Kaphavāta } \\
\text { śāmaka }\end{array}$ \\
\hline 7. & Rāla [16] & $\begin{array}{l}\text { Shorea } \\
\text { robusta }\end{array}$ & Dipterocarpae & $\begin{array}{l}\text { kașāya - } \\
\text { madhura }\end{array}$ & Rūkșa & Síta & Katu & $\begin{array}{l}\text { kuștha, krimi } \\
\text { vināśana }\end{array}$ & $\begin{array}{l}\text { Pittakapha } \\
\text { śāmaka }\end{array}$ \\
\hline 9. & Somala [17] & & & Tikta & Snigdha & & & kușthahara & kușțaghna \\
\hline 10. & Harītakī [18] & $\begin{array}{l}\text { Terminalia } \\
\text { chebula }\end{array}$ & Combretaceae & $\begin{array}{c}\text { pancarasa } \\
\text { (lavaṇavarjita) } \\
\text { kașāya } \\
\text { Pradhāna }\end{array}$ & Laghu,rūkșa & Ūṣna & Madhura & $\begin{array}{c}\text { kuștha, krimihara, } \\
\text { rasāyana }\end{array}$ & Tridoșa śāmaka \\
\hline 11. & āmalakī [19] & $\begin{array}{l}\text { Emblica } \\
\text { officinalis }\end{array}$ & Euphorbiaceae & $\begin{array}{c}\text { pancarasa } \\
\text { (lavanavavarita) } \\
\text { Pradhāna }\end{array}$ & Gurū, rūkșa, śìta & Síta & Madhura & $\begin{array}{l}\text { rasāyana, } \\
\text { kușthaghna }\end{array}$ & Tridoșahara \\
\hline 12. & Vibhitakī [20] & $\begin{array}{l}\text { Terminalia } \\
\text { bellirica }\end{array}$ & Combretaceae & kașāya & Rūkșa, laghu & Ūṣna & Madhura & $\begin{array}{c}\text { Krimihara, } \\
\text { pittaroga vināśana }\end{array}$ & Tridoșahara \\
\hline 13. & Giloya [21] & $\begin{array}{l}\text { Tinospora } \\
\text { cordifolia }\end{array}$ & Menispermaceae & Tikta, kașāya & Gurū, snigdha & Ūṣna & Madhura & $\begin{array}{l}\text { kușthahara, } \\
\text { krimihara }\end{array}$ & Tridoșaśāmaka \\
\hline 14. & $\begin{array}{c}\text { Guggulu } \\
\text { [22] }\end{array}$ & $\begin{array}{c}\text { Commiphora } \\
\text { mukul }\end{array}$ & Burseraceae & Tikta, katu & $\begin{array}{c}\text { Laghu, rūkșa, } \\
\text { vishada,sara, } \\
\text { tridoșa, - purānā, } \\
\text { navīna - snigdha, } \\
\text { picchila }\end{array}$ & Ūṣna & Katu & kușțaghna & Tridoșaahara \\
\hline
\end{tabular}

Table 1: Rasa, Guṇa, Vīrya, Vipāka, Prabhāva \& Doșa Karma of Auṣadhi. 


\section{Observation and Result}
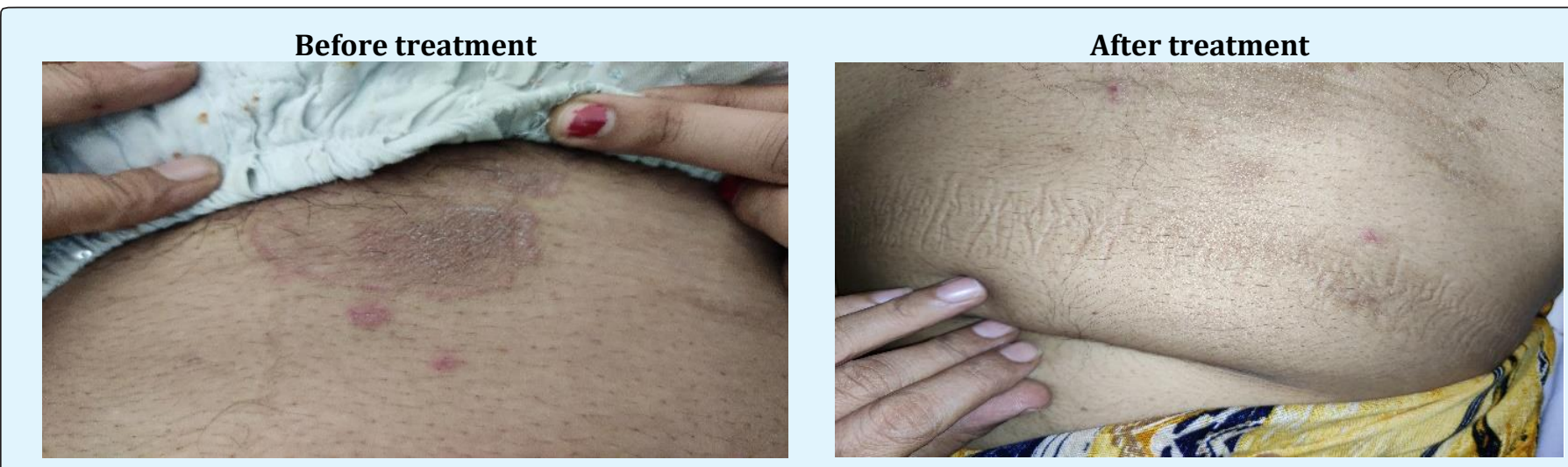

Figure 1: On Lower Abdomen.

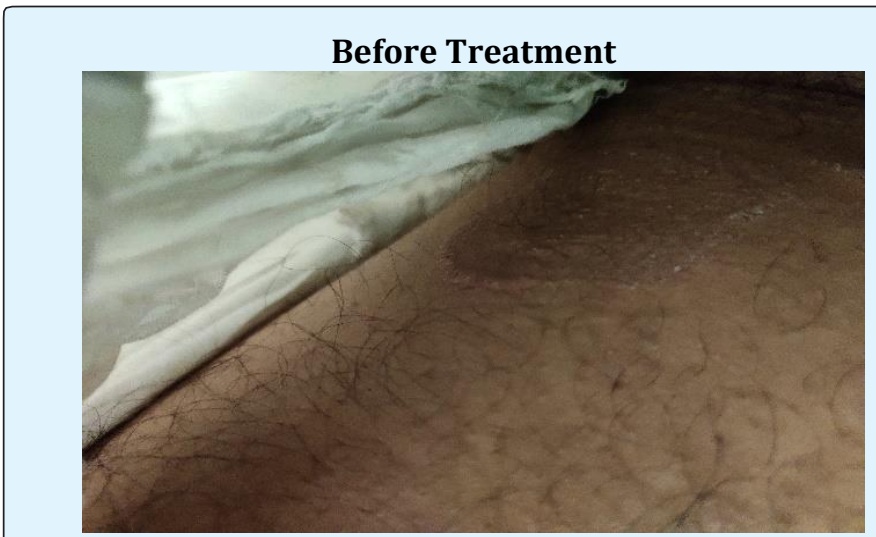

\section{After treatment}

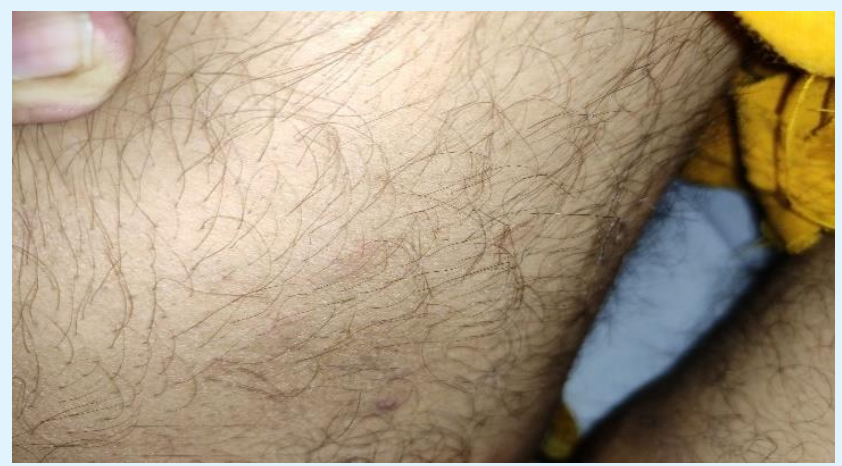

Figure 2: On the left thigh region.
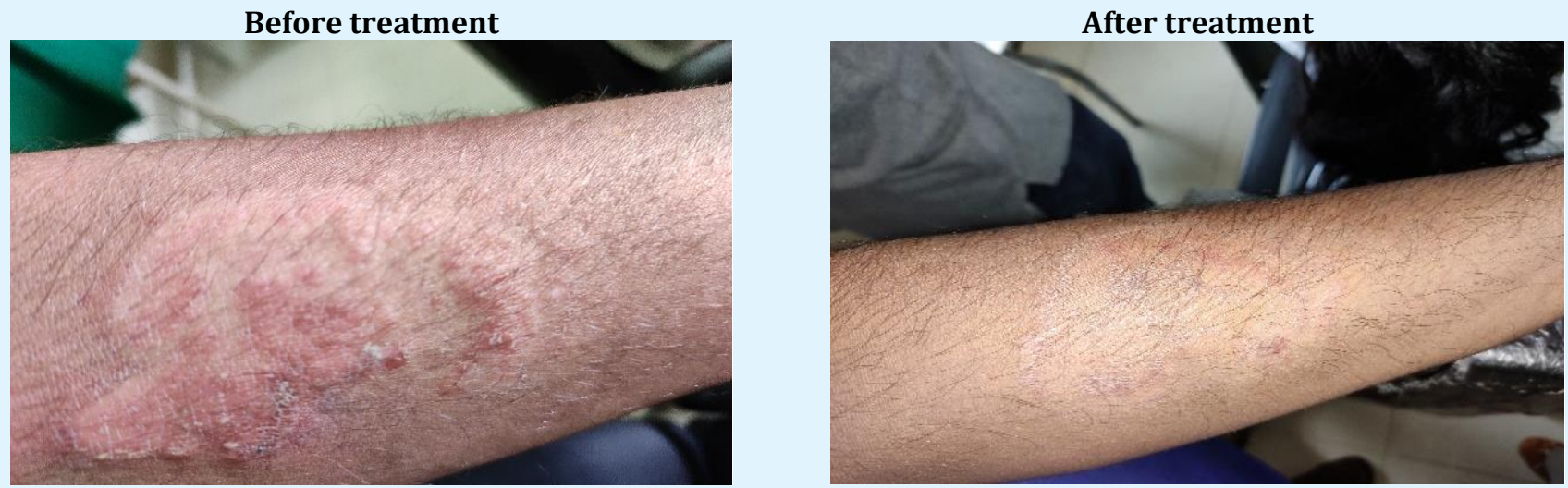

Figure 3: On the left forearm.

During follow up, the (kandu, rāga \& utsanna mandala) symptoms of patient were diminished after taking medicines for seven days \& at this time, patient condition was improved. 


\section{Clinical Dermatology Open Access Journal}

\section{Discussion}

Dadru is pitta kapha vyādhi. Dadru is manifested as discoloured, elevated lesions with severe kandu and rūkșatā and recurrence is possible. It is commonly found in unhygienic and in immune compromised person. In this study, the treatment given is as follows: Malla sindūra, shuddha gandhaka cūrṇa, nimbādi cūrṇa, manjisțhā cūrṇa, haridrākhanḍa, kaiśora guggulu (raktashodhaka action), and dadruharalepa are tridoșa śámaka. Dadruharalepa includes Sarala niryasa, Gandhaka, țankaṇa \& rāla [23]. This lepa is applied locally two times in a day. Kaiśora guggulu includes the contents like triphalā, nim, giloya, guggulu and malla sindūra (Shuddha pārad, ghandhak \& somal) [24]. All these drugs have raktashodhaka property which helps in curing rakta dusți. Rakta dusți is common in all skin diseases. These medicines are dadru nāśaka, krimihara, kușțaghna, kaṇdughana \& varnya. These drugs act as a rasāyana and are also responsible for maintaining the healthy condition of skin. During this study, significant improvement in symptoms (Elevated lesion, itching \& redness) occurs within seven days.

\section{Conclusion}

Dadru is a contagious skin disease which is clinically similar to tinea corporis. So, personal hygiene is very important to maintain in this disease. This present case study cocludes that ayurvedic medicines like Malla sindūra, shuddha gandhaka cūrṇa, nimbādi cūrṇa, manjișțhā cūrṇa, haridrākhanḍa, kaiśora guggulu, and dadruharalepa with some dietary and life style changes are very effective in the treatment of dadru.

\section{References}

1. Srī Cakrapāṇidatta (2017) Agniveśa; caraka samhitā, āyurveda dīpikā. In: Paṇdita yādavajī trikamajī ācārya (Ed.), Caukhambhā surabhāratī prakāśana , Vārāṇasī, cikitsā sthāna, 7(30): 451.

2. Srī Cakraspāṇidatta (2017) Agniveśa; caraka samhitā, āyurveda dīpikā. In: Paṇụita yādavajī trikamajī ācārya (Ed.), caukhambhā surabhāratī prakāśana , vārāṇasī, cikitsā sthāna, 7(23): 451.

3. Srī cakraspāṇidatta (2017) Agniveśa; caraka samhitā, āyurveda dīpikā. In: Panḍita yādavajī trikamajī ācārya, caukhambhā surabhāratī prakāśana , vārāṇasī, Śārīrasthāna, pp: 514.

4. Dalhaṇa (2017) Suśruta; suśruta samhitā with nibandha sangraha. In: Jādavajī trikamajī ācārya (Ed.),
Caukhambhā sanskṛta sansthāna, vārāṇasī, nidānasthāna, 5(8): 284.

5. Srī cakrapāniidatta (2017) Agniveśa; caraka samhitā, āyurveda dīpikā. In: paṇdita yādavajī trikamajī ācārya (Ed.), Caukhambhā surabhāratī prakāśana, Vārāṇasī, Cikitsā sthāna 7(30): 451.

6. Dalhaṇa (2017) Suśruta; suśruta samhitā with nibandha sangraha. In: Jādavajī trikamajī ācārya (Ed.) Caukhambhā sanskṛta sansthāna, Vārāṇasī, Nidānasthāna, 5(7): 284.

7. Dalhaṇa (2017) Suśruta; suśruta samhitā with nibandha sangraha commentary. In: Jādavajī trikamajī ācārya (Ed.), caukhambhā sanskṛta sansthāna, Vārāṇasī, Cikitsā sthāna, 9(6): 442.

8. (2002) Vāgbhațtá; aștāngahṛdaya; commentaries sarvāngasundarā of aruaṇadatta \& āyurveda rasāyana of hemādri. Paṇdita HS pāradakara (Ed.), Annā MK, Sāstri nāvare KR (Annotated), Caukhambhā Orientaliya, vārāṇasī. Nidān sthana 14(33): 527.

9. (2002) Vāgbhațța; așțāngahṛdaya; commentaries sarvāngasundarā of aruaṇadatta \& āyurveda rasāyana of hemādri. Paṇdita HS pāradakara (Ed.); Annā MK, kṛṣna nāvare RS (Annotated), Caukhambhā Orientaliya, Vārānaasī, Nnidān sthana 14(24): 526.

10. Sharma PV (2011) Dravya guṇa vijñānama. Caukhambhā Bhāratī Academy, Vārāṇasī, 2: 800.

11. Sharma PV (2011) Dravya guṇa vijñānama. Caukhambhā Bhāratī Academy, Vārāṇasī, 2: 149.

12. Sharma PV (2011) Dravya guṇa vijñānama. Caukhambhā Bhāratī Academy, Vārāṇasī, 2: 162.

13. Sharma PV (2011) Dravya guṇa vijñānama. Caukhambhā Bhāratī Academy, Vārāṇasī, 2: 214.

14. Sharma PV (2011) Dravya guṇa vijñānama. Caukhambhā Bhāratī Academy, Vārāṇasī, 2: 308.

15. Chandra bhushan Jha (2016) Āyurvedīya rasaśāstra. Caukhambhā Surbhāratī prakāśana, Vārāṇasī, pp: 241.

16. Sharma PV (2011) Dravya guṇa vijñānama. Caukhambhā Bhāratī Academy, Vārāṇasī, 2: 672.

17. Chandra bhushan Jha (2016) Āyurvedīya rasaśāstra. Ccaukhambhā Surbhāratī prakāśana, Vārāṇasī, pp: 276. 


\section{Clinical Dermatology Open Access Journal}

18. Sharma PV (2011) Dravya guṇa vijñānama. Caukhambhā Bhāratī Academy, Vārāṇasī, 2: 753.

19. Sharma PV (2007) Dravya guṇa vijñānama. Caukhambhā Bhāratī Academy, Vārāṇasī, 2: 758.

20. Sharma PV (2007) Dravya guṇa vijñānama. Caukhambhā Bhāratī Academy, Vārāṇasī, 2: 239.

21. Sharma PV (2007) Dravya guna vijñānama. Caukhambhā Bhāratī Academy, Vārāṇasī, 2: 761.
22. Sharma PV (2007) Dravya guṇa vijñānama. Caukhambhā Bhāratī Academy, Vārāṇasī, 2: 54.

23. Rasa tantra sāra evam siddhaprayoga sangraha kṛṣna gopāla āyurveda bhavan. Ajmer, 2: 2.

24. Rasa tantra sāra evam siddhaprayoga sangraha kṛ̦̣na gopāla granthamālā, kṛ̦ṇa gopāla āyurveda bhavan, Ajmer, 2: 474. 